\title{
Gambaran pengetahuan ibu tentang makanan pendamping ASI (MP-ASI) pada anak usia 6-24 bulan
}

\author{
Putri Eka Sudiarti ${ }^{1}$, Meri Neherta$^{2}$, Deswita ${ }^{3}$ \\ 1,2,3 Fakultas Keperawatan Universitas Andalas, Padang, Indonesia. Email: putriekasugiarti@gmail.com
}

\begin{abstract}
Mother's knowledge about complementary foods on infant children aged 6-24 months in Kampar, Riau-Indonesia
\end{abstract}

Background: Problems with children's nutritional status can cause mortality and morbidity in children. The problem of nutritional status in children under five is caused by the lack of mother's knowledge about complementary feeding.

Purpose: This study aims to determine an overview of mother's knowledge about complementary foods on infant children aged 6-24 months.

Methods: The study method used descriptive method. The population of the study was mothers who had children aged 6-24 months in the Kampar District. Sampling technique used Random sampling technique with Multi Stage sampling obtained a sample of 75 people in the Tambang and Bangkinang Public health center. The study instrument used questioner. The analysis technique used descriptive quantitative.

Results: The results of study showed that $64 \%$ of mothers had sufficient knowledge and $36 \%$ of mothers had moderate knowledge.

Conclusion: The conclusion of the study was the majority of mothers' knowledge who had children aged 6-24 months about complementary foods on infant were in sufficient range. It is necessary to conduct nutritional education on complementary feeding to increase mothers' knowledge about complementary feeding.

\section{Keywords: Mothers knowledge; Complementary foods; Infant children; Aged 6-24 months}

Pendahuluan: Permasalahan status gizi anak dapat menyebabkan mortalitas dan morbiditas pada anak. Permasalahan status gizi pada anak usia balita salah satunya disebabkan oleh rendahnya pengetahuan ibu mengenai MP-ASI.

Tujuan: Diketahui gambaran pengetahuan ibu mengenai MP-ASI anak usia 6-24 bulan.

Metode: Metode penelitian menggunakan metode deskriptif. Populasi penelitiana adalah ibu yang memiliki anak usia 6-24 bulan di wilayah Kabupaten Kampar. Teknik pengambilan Sampel menggunakan teknik randome sampling dengan Multi Stage Sampling dan didapatkan sampel berjumlah 75 orang pada wilayah Puskesmas Tambang dan Bangkinang. Instrumen penelitian menggunakan kuisioner. Teknik analisa menggunakan deskriptif kuantitatif.

Hasil: Hasil penelitian menunjukkan bahwa sebesar $64 \%$ ibu memiliki pengetahuan cukup dan $36 \%$ persen ibu memiliki pengetahuan sedang.

Simpulan: Penelitian didapatkan bahwa mayoritas pengetahuan ibu anak usia 6-24 bulan mengenai MP-ASI berada pada rentang cukup. Perlu dilakukannya edukasi gizi mengenai MP-ASI untuk meningkatkan pengetahuan ibu mengenai MP-ASI.

\section{Kata Kunci: Pengetahuan ibu; MP-ASI; Anak usia 6-24 bulan}

\section{PENDAHULUAN}

Permasalahan gizi pada anak adalah permasalahan kesehatan yang menyebabkan peningkatan mortalitas dan morbiditas pada anak. Permasalahan gizi terjadi dalam berbagai macam seperti anak kurus (wasting), anak pendek (stunting), dan anak dengan kelebihan berat badan (obesity) (World Health Organization, 2017). Permasalahan gizi terbanyak yang terjadi pada anak adalah stunting sebesar $23,8 \%$ dibandingkan dengan masalah gizi lainnya seperti anak kurus $11 \%$ dan anak dengan kelebihan berat badan $6 \%$

Putri Eka Sudiarti', Meri Neherta ${ }^{2}$, Deswita ${ }^{3}$ Fakultas Keperawatan Universitas Andalas, Padang, Indonesia.

Email: putriekasugiarti@gmail.com 
Gambaran pengetahuan ibu tentang makanan pendamping ASI (MP-ASI) pada anak usia 6-24 bulan

(Achadi, Ahuja, Bendech, Bhutta, Regil, Fanzo, \& Kimani, 2016). Pada tahun 2017 terdapat 29,6\% anak stunting, 9,5\% anak wasting dan $44,6 \%$ anak overweight di Indonesia (Kementerian Kesehatan Republik Indonesia, 2018).

Permasalahan gizi pada anak akan meningkatkan morbiditas dan mortalitas. Anak wasting risiko tinggi akan morbiditas dibandingkan dengan anak normal. Sedangkan anak overweight akan rentan mengalami penyakit degeneratif saat dewasa nanti (United Nations Children's Fund, 2018). Kondisi lain seperti stunting pada anak akan memberikan dampak pada fisik, anak akan menjadi pendek (World Health Organization, 2018). Hal ini akan terjadi pada lintas generasi selanjutnya (Trihono, Tjandrarini, Irawati, Utami, Tejayanti, \& Nurlinawati, 2015). Anak stunting juga akan mengalami gangguan pada kognitifnya dan penurunan produktifitas sebasar $20 \%$ ketika dewasa nanti (Perkins, Kim, Krishna, McGovern, Aguayo, \& Subramanian, 2017).

Anak stunting disebabkan oleh kekurangan gizi pada 1000 hari pertama kehidupan (HPK) (Trihono, et al., 2015). Faktor yang berkontribusi terhadap anak dengan permasalahan gizi stunting adalah bagaimana ketidakadekuatan pemberian ASI dan MP-ASI pada anak usia 6-24 bulan (Stewart, lannotti, Dewey, Michaelsen, \& Onyango, 2013).

Asupan gizi balita dipengaruhi oleh bagaimana pengetahuan ibu dalam pemilihan ragam makanan yang akan diberikan kepada balita. Semakin tinggi pengetahuan ibu maka status gizi anakpun akan semakin baik (Uliyanti, Tamtono, \& Anantayu, 2017). Hasil penelitian terdahulu menunjukkan bahwa pengetahuan ibu mengenai gizi dan asupan makan balita adalah faktor yang berpengaruh terhadap status gizi balita (Puspasari, \& Andriani, 2017). Pengetahuan ibu mengenai kesehatan akan mempengaruhi bagaimana pola tindakan ibu dalam pemenuhan gizi balita (Rahmatillah, 2018).
Peran ibu sangatlah penting dalam pemenuhan gizi terutama dalam memilih dan mempersiapkan makanan yang akan dikonsumsi balita (Uliyanti, Tamtono, \& Anantayu, 2017). Gizi yang adekuat akan menunjang pertumbuhan dan perkembangan yang optimal pada anak usia 6-24 bulan sehingga anak tidak memiliki permasalahan dalam status gizi (Kyle, 2013). Pemberian gizi yang adekuat pada balita dapat berkontribusi pada pertumbuhan dan perkembangan balita (Heidkamp, Ayoya, Teta, Stoltzfus, \& Marhone, 2015).

\section{METODE PENELITIAN}

Penelitian ini mengunakan rancangan penelitian deskriptif, bertujuan melihat bagaimana gambaran pengetahuan ibu mengenai MP-ASI pada anak usia 6-24 bulan. Penelitian dilaksanakan pada bulan Januari hingga Februari 2019. Populasi penelitian adalah ibu yang memiliki balita usia 6-24 bulan di Kabupaten Kampar. Penentuan sampel menggunakan Multi Stage Sampling dengan melihat daerah yang memliki permasalahan gizi yang tinggi. Sampel berjumlah 75 ibu dari wilayah kerja Puskesmas Tambang dan Bangkinang Kabupaten Kampar, Provinsi Riau.

Pengumpulan data dilakukan dengan menggunakan kuisioner yang terdiri dari data karakteristik ibu yang terdiri dari usia, pendidikan, status pekerjaan ibu, dan penghasilan keluarga. Selain itu juga terdapat kuisioner pengetahuan mengenai MP-ASI anak usia 6-24 bula yang terdiri dari 8 item pertanyaan.

Teknik analisa data menggunakan analisa data univariat untuk melihat tingkat pengetahuan ibu dengan menampilkan frekuensi dan persentase. lbu berpengetahuan rendah jika hasil persentase kurang dari $56 \%$, ibu dikatakan berpengetahuan cukup jika persentase pengetahuan $56 \%-75 \%$, dan ibu dikatakan berpengetahuan baik jika persentase pengetahuan lebih $75 \%$.

Putri Eka Sudiarti', Meri Neherta ${ }^{2}$, Deswita ${ }^{3}$ Fakultas Keperawatan Universitas Andalas, Padang, Indonesia.

Email: putriekasugiarti@gmail.com 
HASIL

Tabel 1. Karakteristik Responden $\mathrm{N}=75$

\begin{tabular}{lcc}
\hline Variabel & Jumlah (n) & Persentase (\%) \\
\hline Usia & & \\
$<20$ & 11 & 14,7 \\
$21-35$ & 51 & 68 \\
$>35$ & 13 & 17 \\
& & \\
Pendidikan & & \\
SD sederajat & 15 & 20 \\
SMP sederajat & 11 & 14,7 \\
SMA sederajat & 33 & 44 \\
DIII/S1/S2 & 16 & 21,3 \\
Status Pekerjaan & & \\
Tidak Bekerja & & \\
Bekerja & 64 & 85 \\
Pendapatan Keluarga & 11 & 14,7 \\
<Rp. 1500.000 & & \\
Rp. 1.500.000 - & 21 & 28 \\
Rp. 3.500 .00 & 43 & 57,3 \\
$>3.500 .000$ & 11 & 14,7 \\
\hline
\end{tabular}

Table 1. menunjukkan sebagian besar ibu berusia 21-35 tahun yaitu sebsar $68 \%$. Sekitar $44 \%$ ibu berlatar pendidikan SMA sederajat dan $85 \%$ ibu tidak bekerja. Terdapat 57,3\% pendapatan keluarga berkisar antara Rp. 1.500.000 hingga Rp.3.500.000.

Tabel 2. Tingkat Pengetahuan Ibu Mengenai MP-ASI N=75

\begin{tabular}{ccc}
\hline Tingkat Pengetahuan & Jumlah $(\mathbf{n})$ & Persentase (\%) \\
\hline Kurang & 27 & 36 \\
Cukup & 48 & 64 \\
\hline
\end{tabular}

Table 2. menunjukkan bahwa dari 75 ibu yang menjadi sampel penelitian didapatkan sekitar $64 \%$ ibu memiliki pengetahuan cukup dan $36 \%$ ibu memiliki pengetahuan kurang.

Tabel 3. Distribusi Persentase Kuisioner Pengetahuan Ibu mengenai MP-ASI N=75

\begin{tabular}{|c|c|c|}
\hline \multirow[t]{2}{*}{ Kuisioner Pengetahuan } & \multicolumn{2}{|c|}{ Persentase Jawaban } \\
\hline & Benar & Salah \\
\hline Pemberian ASI hingga anak usia 24 bulan & $76 \%$ & $24 \%$ \\
\hline MP-ASI mulai usia 6 bulan & $73,3 \%$ & $26,7 \%$ \\
\hline MP-ASI anak usia 6 bulan diberikan Makanan Lumat & $73,3 \%$ & $26,7 \%$ \\
\hline Nasi tim saring contoh makanan lumat & $60 \%$ & $40 \%$ \\
\hline Pentingnya pemberian MP-ASI mulai usia 6 bulan & $48 \%$ & $52 \%$ \\
\hline Aneka ragam MP ASI yang sesuai dengan kebutuhan gizi anak usia 6-24 bulan & $44 \%$ & $56 \%$ \\
\hline Frekuensi pemberian makanan utama dan selingan MP-ASI & $33 \%$ & $66,7 \%$ \\
\hline Cara meningkatkan nafsu makan anak & $80 \%$ & $20 \%$ \\
\hline
\end{tabular}

Putri Eka Sudiarti', Meri Neherta ${ }^{2}$, Deswita ${ }^{3}$ Fakultas Keperawatan Universitas Andalas, Padang, Indonesia.

Email: putriekasugiarti@gmail.com 
Gambaran pengetahuan ibu tentang makanan pendamping ASI (MP-ASI) pada anak usia 6-24 bulan

Tabel 3. menunjukkan distribusi persentase jawaban kuisioner pengetahuan ibu mengenai MP-ASI. Item pertanyaan frekuensi pemberian makanan utama dan selingan MP-ASI adalah item pertanyaan yang memiliki persentase nilai terendah yaitu $33 \%$ dan cara peningkatan nafsu makan anak memiliki persentase item pertanyaan tertinggi $80 \%$.

\section{PEMBAHASAN}

Pada penelitian ini mayoritas ibu berusia 21-35 tahun, dimana menurut usia ini pada wanita adalah tahap tanggung jawab dalam mengasuh pola gizi balita dan hal tersebut merupakan suatu yang wajar (Potter, \& Perry, 2013). Penelitian ini sejalan dengan penelitian terdahulu bahwa $97 \%$ ibu berusia 21-40 tahun (Setyaningsih, \& Agustini, 2017).

Pengetahuan merupakan hasil pengamatan pada suatu objek melalui indera penciuman (hidung), indera penglihatan (mata), indera pendengaran (telinga), dan indera lainnya (Notoatmodjo, 2014). Pengetahuan dapat dikategorikan dengan skala kualitatif yaitu individu dikatakan berpengetahuan baik jika persentase nilai pengetahuan antara $76 \%$ hingga $100 \%$. Individu dikatakan berpengetahuan cukup jika persentase nilai pengetahuan berkisar $56 \%$ hingga $75 \%$ dan individu berpengetahuan kurang jika persentase nilai pengetahuan kurang dari $56 \%$ (Wawan, \& Dewi, 2013).

Hasil penelitian ini menunjukkan bahwa sekitar $64 \%$ ibu memiliki pengetahuan cukup dan sekitar $34 \%$ ibu memiliki pengetahuan kurang dan tak satupun ibu memiliki pengetahuan baik. Serupa dengan penelitian sebelumnya bahwa $75 \%$ ibu memiliki pengetahuan cukup dan hanya $4,5 \%$ ibu memiliki pengetahuan kurang serta $19,6 \%$ ibu berpengetahuan baik (Setyaningsih, \& Agustini, 2017). Hal yang berbeda ditemukan pada hasil penelitian lain yang menunjukkan bahwa mayoritas pengetahuan ibu mengenai MP-ASI berada pada tingkat baik yaitu $88 \%$ dan hanya sekitar $12 \%$ ibu yang berpengetahuan rendah (Berisha, Ramadani, Hoxha, Gashi, Zhjeqi, Zajmi, \& Begolli, 2017).

Melihat pada data karakteristik latar belakang pendidikan ibu adalah mayoritas ibu berpendidikan tingkat SMA atau sederajat. Salah satu faktor yang mempengaruhi pengetahuan adalah faktor latar belakang pendidikan. Semakin tinggi pendidikan seseorang, maka semakin mudah ia dalam menerima informasi (Wawan, \& Dewi, 2013). Ibu dengan tingkat pendidikan yang lebih tinggi yaitu SMA dan Perguruan Tinggi akan memiliki pengetahuan yang lebih baik mengenai MP-ASI (Berisha, et al., 2017).
Pada tabel 3. item pertanyaan nomor 7 adalah item yang memiliki jumlah jawaban benar yang paling sedikit jika dibandingkan dengan pertanyaan lainnya. Item pertanyaan nomor 7 meliputi frekuensi pemberian makan utama dan selingan MP-ASI dalam sehari. Hanya sebesar 33\% ibu yang menjawab benar. Dan item pertanyaan 8 adalah item yang memiliki nilai tertinggi ibu dengan jawaban benar yaitu $80 \%$.

Anak usia 6-8 bulan mendapatkan MP-ASI sebanyak 2-3 kali dan anak usia 9-24 bulan mendapatkan 3-4 kali sehari dengan makanan selingan sebanyak 1-2 kali (Hardinsyah, \& Supariasa, 2016). Hasil penelitian sebelumnya juga memaparkan hasil yang tidak jauh berbeda dengan penelitian ini yaitu pengetahuan mengenai frekuensi pemberian MP-ASI pada anak menunjukkan nilai yang rendah yaitu $55,3 \%$ ibu yang mengetahuinya. Namun pada penelitiannya ditemukan persentase yang terendah yaitu pada pertanyaan mengenai pemberian zat besi, zinc dan vitamin saat usia 6 bulan anak sebesar $39,4 \%$ (Berisha, et al., 2017).

Frekuensi pemberian MP-ASI dalam sehari pada balita merupakan salah satu bagian prinsip pemberian MP-ASI anak usia 6-24 bulan (Mufida, Widyaningsih, \& Maligan, 2015). Pemberian MPASI anak usia 6-24 bulan yang tidak adekuat menjadi salah satu faktor terjadinya permasalahan gizi pada 1000 HPK (Kim, Guevara, Corsi, Aguayo, \& Subramanian, 2017).

Peningkatan pengetahuan dapat dilakukan dengan adanya pemberian edukasi gizi (Hardinsyah, \& Supariasa, 2016). Edukasi gizi memberikan perubahahan yang signifikan pada pengetahuan ibu (Kusumawati, Rahardjo, \& Sistiarani, 2017).

\section{SIMPULAN}

Mayoritas pengetahuan ibu anak usia 6-24 bulan mengenai MP-ASI berada pada rentang cukup. Mayoritas ibu tidak mengetahui frekuensi pemberian makanan utama dan makanan selingan MP-ASI sesuai dengan tahap usia anak. Perlu dilakukannya edukasi gizi mengenai MP-ASI terhadap ibu maupun keluarga bayi agar dapat meningkatkan status gizi bayi.

Putri Eka Sudiarti', Meri Neherta ${ }^{2}$, Deswita ${ }^{3}$ Fakultas Keperawatan Universitas Andalas, Padang, Indonesia.

Email: putriekasugiarti@gmail.com 
Gambaran pengetahuan ibu tentang makanan pendamping ASI (MP-ASI) pada anak usia 6-24 bulan

\section{SARAN}

Peneliti berharap penelitian ini dapat menjadi tambahan informasi dan juga peneliti berharap kepada peneliti selanjutnya agar dapat mengembangkan penelitian ini dengan melihat faktor-faktor yang mempengaruhi pengetahuan ibu mengenai MP-ASI.

\section{DAFTAR PUSTAKA}

Achadi, E., Ahuja, A., Bendech, M. A., Bhutta, Z. A., Regil, L. M., Fanzo, J. \& Kimani, E. (2016). Global nutrition report 2016: From promise to impact: Ending malnutrition by 2030. International Food Policy Research Institute.

Berisha, M., Ramadani, N., Hoxha, R., Gashi, S., Zhjeqi, V., Zajmi, D., \& Begolli, I. (2017). Knowledge, Attitudes and Practices of Mothers in Kosova About Complementary Feeding for Infant and Children 6-24 Months. Medical Archives, 71(1), 37.

Hardinsyah, M. S., \& Supariasa, I. D. (2016). IImu gizi teori dan aplikasi. Jakarta: EGC.

Heidkamp, R. A., Ayoya, M. A., Teta, I. N., Stoltzfus, R. J., \& Marhone, J. P. (2015). Complementary feeding practices and child growth outcomes in Haiti: An analysis of data from Demographic and Health Surveys. Maternal and Child Nutrition, 11(4), 815-828.

Kementerian Kesehatan Republik Indonesia. (2018). Buku Saku Pemantauan Status Gizi Tahun 2017. Jakarta. Kemenkes RI.

Kim, R., Guevara, I., Corsi, D. J., Aguayo, V. M., \& Subramanian, S. V. (2017). Relative importance of 13 correlates of child stunting in South Asia: Insights from nationally representative data from Afghanistan, Bangladesh, India, Nepal, and Pakistan. Social Science and Medicine, 187, 144-154.

Kusumawati, E., Rahardjo, S., \& Sistiarani, C. (2017). Multilevel Intervention Model to Improve Nutrition of Mother and Children in Banyumas Regency. KEMAS: Jurnal Kesehatan Masyarakat, 12(2), 277-285.

Kyle, T. (2013). Essentials of pediatric nursing. Lippincott Williams \& Wilkins.
Mufida, L., Widyaningsih, T. D., \& Maligan, J. M. (2015). Prinsip Dasar Makanan Pendamping Air Susu Ibu (MP-ASI) Untuk Bayi 6-24 Bulan: Kajian Pustaka [In Press September 2015]. Jurnal Pangan dan Agroindustri, 3(4).

Notoatmodjo, S. (2014). Promosi Kesehatan dan Perilaku Kesehatan. Jakarta: Rineka Cipta.

Perkins, J. M., Kim, R., Krishna, A., McGovern, M., Aguayo, V. M., \& Subramanian, S. V. (2017). Understanding the association between stunting and child development in low- and middle-income countries: Next steps for research and intervention. Social Science and Medicine, 193, 101-109.

Potter, P. A., \& Perry, A. G. (2013). Fundamentals Of Nursing. (Elsevier, Ed.) (8th ed.). Canada: Elsevier Inc.

Puspasari, N., \& Andriani, M. (2017). Hubungan Pengetahuan lbu tentang Gizi dan Asupan Makan Balita dengan Status Gizi Balita (BB/U) Usia 12-24 Bulan. Amerta Nutrition, 1(4), 369378.

Rahmatillah, D. K. (2018). Hubungan Pengetahuan Sikap dan Tindakan terhadap Status Gizi. Amerta Nutrition, 2(1), 106-112.

Setyaningsih, S. R., \& Agustini, N. (2014). Pengetahuan, Sikap, dan Perilaku Ibu dalam Pemenuhan Gizi Balita: Sebuah Survei. Jurnal Keperawatan Indonesia, 17(3), 88-94.

Stewart, C. P., lannotti, L., Dewey, K. G., Michaelsen, K. F., \& Onyango, A. W. (2013). Contextualising complementary feeding in a broader framework for stunting prevention.Maternal \& child nutrition, 9, 27-45.

Trihono, A., Tjandrarini, D. H., Irawati, A., Utami, N. H., Tejayanti, T., \& Nurlinawati, I. (2015). Pendek (stunting) di Indonesia, masalah dan solusinya. Jakarta: Badan Penelitian dan Pengembangan Kesehatan.

Uliyanti, U., Tamtomo, D. G., \& Anantanyu, S. (2017). Faktor yang berhubungan dengan kejadian stunting pada balita usia 24-59 bulan. Jurnal Vokasi Kesehatan, 3(2), 67-77.

Putri Eka Sudiarti', Meri Neherta ${ }^{2}$, Deswita ${ }^{3}$ Fakultas Keperawatan Universitas Andalas, Padang, Indonesia.

Email: putriekasugiarti@gmail.com 
Gambaran pengetahuan ibu tentang makanan pendamping ASI (MP-ASI) pada anak usia 6-24 bulan

United Nations Children's Fund. (2018). Levels and trends in child malnutrition. eSocialSciences.

Wawan, A., \& Dewi, M. (2013). Teori dan pengukuran pengetahuan, sikap dan perilaku manusia. Yogyakarta: Nuha Medika.
World Health Organization. (2017). Guideline: assessing and managing children at primary health-care facilities to prevent overweight and obesity in the context of the double burden of malnutrition. World Health Organization.

World Health Organization. (2018). Reducing stunting in children: equity considerations for achieving the global nutrition targets 2025 .

Putri Eka Sudiarti', Meri Neherta ${ }^{2}$, Deswita ${ }^{3}$ Fakultas Keperawatan Universitas Andalas, Padang, Indonesia. Email: putriekasugiarti@gmail.com 